\title{
Subtle and Overt Forms of Islamophobia: Microaggressions toward Muslim Americans
}

\author{
Kevin L. Nadal
}

\author{
Katie E. Griffin, Sahran Hamit, Jayleen Leon, Michael \\ Tobio \\ John Jay College of Criminal Justice-City University of New York
}

\section{David P. Rivera}

Teachers College-Columbia University

\begin{abstract}
Previous research suggests that microaggressions, or subtle and covert manifestations of bias, are commonplace in the life experience of people of color, women, and sexual minorities. However, there is a dearth of research focusing on microaggressions toward people from religious minority groups. Using a qualitative approach and directed content analysis with Muslim American participants $(N=10)$, six themes emerged: 1) Endorsing Religious Stereotypes of Muslims as Terrorists, 2) Pathology of the Muslim Religion, 3) Assumption of Religious Homogeneity, 4) Exoticization, 5) Islamophobic and Mocking Language, and 6) Alien in Own Land. Implications for Muslim mental health are discussed.
\end{abstract}

Keywords: Muslims, Islam, religion, microaggression, discrimination, bias

\section{Subtle and Overt Forms of Islamophobia: Microaggressions toward Muslim Americans}

In recent years, there has been an emergence of research regarding racial microaggressions, or subtle forms of discrimination (often unintentional and 
unconscious) that send negative and denigrating messages to members of marginalized racial groups (Nadal, 2011; Sue, 2010). Microaggressions tend to leave targets feeling angry and confused, often wondering if race was involved in an interaction, or whether or not to confront the perpetrator. Studies have found that the process of encountering racial microaggressions can be psychologically and physically draining, often to leading to higher levels of stress and poor mental health outcomes (Nadal, Wong, et al., 2011; Rivera, Forquer, \& Rangel, 2010; Sue, Bucceri, Lin, Nadal, \& Torino, 2007; Sue, Capodilupo, \& Holder, 2008; Sue, Nadal, Capodilupo, Lin, Torino, \& Rivera, 2008). While the most well-known literature on microaggressions has focused on subtle forms of discrimination toward racial and ethnic minority groups (e.g., Nadal, 2011; Pierce, Carew, Pierce-Gonzalez, \& Willis, 1973; Sue, Capodilupo, Torino, Bucceri, Holder, Nadal, et al., 2007, Sue 2010), there has been an increase in the literature focusing on microaggressions toward women (Capodilupo et al., 2010; Nadal, 2010), lesbian, gay, bisexual, and transgender (LGBT) people (Nadal, Issa, et al., 2011; Nadal, Rivera, \& Corpus, 2010; Shelton \& Delgado-Romero, 2011), persons with disabilities (Keller \& Galgay, 2010), and religious minorities (Nadal, Issa, Griffin, Hamit, \& Lyons, 2010). Despite this increase in the literature, microaggressions based on religion are presently the least studied, which may result in the lack of understanding of their impacts on members of religious minority groups.

One religious minority group in the United States that is often ignored in the psychological literature is Muslim Americans. There are approximately six to seven million individuals in the US who identify as Muslim, and the population increases significantly every year (Bukhari, 2003; Strum, 2003). Like any other religious or ethnic group, Muslims are diverse in a multitude of ways. They belong to different racial and ethnic groups-approximately one-third of the population is South Asian, about one-fourth is Arab, and about one-fifth of the population is of African descent (Bukhari, 2003). About 69 percent of Muslims in the US are immigrants from over 80 different countries (Strum, 2003), and they reside in various areas across the United States. Finally, Muslim Americans in general tend to be younger, more educated, and more financially wealthy than the general American population (Bukhari, 2003; Strum, 2003).

There are multitudes of ways in which Muslims in the US and abroad have been victims of Islamophobia (Lopez, 2011; Nadal, Issa, et al., 2010). In fact, several reports have discussed the increase of hate crimes and discrimination toward Muslim Americans, particularly after the 9/11 attacks and the subsequent wars in Iraq and Afghanistan (Council of American Islamic Relations [CAIR], 2003, 2008; Rippy \& Newman, 2006). In 2002, there were an array of hate crimes that were reported against Muslims across the US, including the burning of mosques, bomb threats, physical and verbal assaults, and discrimination in employment (Rippy \& Newman, 2006). In 2007, there were 2,652 
reported cases of civil-rights violations against Muslims in the US, including 141 reported cases of passenger profiling and 613 reported cases of hate mail (CAIR, 2008). Previous research has found that Muslim individuals who perceived religious discrimination had an increased likeliness of suspicion, vigilance, and mistrust (Rippy \& Newman, 2006) and even mental and physical health problems (Kira et al., 2010; Sheridan, 2006). Thus, it is evident that blatant religious discrimination is detrimental to Muslim American individuals and communities.

Despite this literature involving Muslim people and overt discrimination, there are no known studies that examine the experiences of religious microaggressions, or subtle forms of religious discrimination, toward Muslim people in the US (Nadal, 2008; Nadal, Issa, et al., 2010). Furthermore, while there has been research that has reported the negative impact of microaggressions on people of color, women, LGBT individuals, and persons with disabilities, it is unknown whether Muslim people who experience microaggressions would have similar experiences and reactions.

A theoretical taxonomy was proposed to identify the types of microaggressions experienced by religious minority groups, including several examples focusing on Islamophobic microaggression toward Muslims (Nadal, Issa, et al., 2010). These authors contended that while there are several types of microaggressions based on religion, it is difficult to definitively attribute certain discriminatory behavior to religious prejudice because of the possibilities that racial or ethnic prejudice are involved as well. Thus, the taxonomy presented six major categories of microaggressions that are based primarily on religion and are likely independent of race, ethnicity, or other variables. These six categories included:

1. Endorsing Religious Stereotypes: statements or behaviors that communicate false, presumptuous, or incorrect perceptions of certain religious groups (e.g., stereotyping that a Muslim person is a terrorist or that a Jewish person is cheap).

2. Exoticization: instances where people view other religions as trendy or foreign (e.g., an individual who dresses in a certain religion's garb or garments for fashion or pleasure).

3. Pathology of Different Religious Groups: Statements and behaviors in which individuals equate certain religious practices or traditions as being abnormal, sinful, or deviant (e.g., telling someone that they are in the "wrong" religion).

4. Assumption of One's Own Religious Identity as the Norm: Comments or behaviors that convey people's presumption that their religion is the standard and behaves accordingly (e.g., greeting someone "Merry Christ- 
mas" or saying "God bless you" after someone sneezes conveys one's perception that everyone is Christian or believes in God).

5. Assumption of Religious Homogeneity: Statements in which individuals assume that every believer of a religion practices the same customs or has the same beliefs as the entire group (e.g., assuming that all Muslim people wear head coverings).

6. Denial of Religious Prejudice: Incidents in which individuals claim that they are not religiously biased, even if their words or behaviors may indicate otherwise.

A large amount of the literature on microaggressions toward other groups began with similar taxonomies, which led to qualitative research that validated the proposed theories. For example, research on African Americans (Sue, Nadal, et al., 2008); Latina/os (Rivera et al., 2010); Asian Americans (Sue, Bucceri, et al., 2007); women (Capodilupo et al., 2010); lesbian, gay, bisexual, and transgender people (Nadal, Issa, et al., 2011); and people with disabilities (Keller \& Galgay, 2010) were all conducted to test previous taxonomies of racial, gender, sexual identity, and ability microaggressions. However, Nadal, Issa, and colleagues' (2010) taxonomy of religious microaggressions has yet to be examined or supported by Muslims or members of any religious minority group. Thus, the current study aimed to examine the following research questions:

1. Do Muslims experience religious microaggressions?

2. What types of microaggressions do Muslims experience?

3. How do Muslims react to, or cope with, microaggressions when they occur?

\section{Method}

The current investigation used a qualitative method to collect and analyze data to gain a deeper understanding of Muslim's experiences with religious microaggressions. Qualitative research has been found to be appropriate when the phenomenon of study has received little empirical attention (Morrow \& Smith, 2000). Focus group methodology, in particular, allows for exploration of a new area of investigation (Krueger \& Casey, 2008) and creates a scope for members of disenfranchised groups to frame their accounts (Fine, 1992). In focus groups, participants are encouraged to share their point of view without necessarily coming to consensus (Krueger \& Casey, 2008), providing an integrated description of the phenomena of study. The group discussion is conducted several times with similar types of participants within a population, to allow 
researchers to identify patterns and themes (Krueger \& Casey, 2008). In the current pilot study, directed content analysis was used to systematically classify, code, and categorize data regarding religious microaggressions experienced by Muslim Americans into themes.

\section{Participants}

Participants were recruited in two ways: (a) email requests were sent to various Muslim interest groups and Muslim college student organizations in the greater New York tri-state region; and (b) participants were requested from the Research Experience Program at a large public university in the New York City area, in which Psychology 101 students are required to participate in research studies on campus as part of their course credit. In order to participate in this study, individuals needed to identify as Muslim and be at least 18 years of age. A total of 10 Muslims participated in the study. There were two focus groups with five participants each. There were seven female participants and three male participants, and participants' ages ranged from 18-50 (mean age: 24.5). The majority of the participants were undergraduate students $(\mathrm{N}=9)$. Participants identified diverse racial backgrounds, including Arab, Asian, African-American/Arab, Caucasian, and "other"; participants also identified various ethnicities including Palestinian, Guyanese, Kazakh, East African/Indian, Egyptian, and Italian/Polish. Finally, because microaggressions are often based on physical appearance, the observers made note of which participants were wearing traditional Muslim garb (e.g., a hijab or a $k u f i$ ); in the current sample, there were three women were wore a hijab. Table 1 includes a list of the various participants' self-reported gender, race, ethnic background, and the observer's perceptions of their clothing.

\section{Researchers}

A crucial aspect of qualitative inquiry involves identifying the researchers' biases and assumptions, as these can potentially influence the data collection and analysis process (Fassinger, 2005). As such, the research team met prior to data collection and again before data analysis to freely discuss their assumptions and beliefs. Moreover, the researchers recognized that their own social identities may influence data collection and analysis; they discussed how their own experiences may affect their interpretations, in order to minimize the bias that could potentially occur. The research team was comprised of eight individuals: one Arab female, one Asian male, one Black female, two Black males, one Latina female, one White female, and one White male. One researcher is a college professor, and seven others are graduate or undergraduate students; none of the researchers identified as actively practicing Islam. 
TABLE 1. Participants' self-reported gender, race, ethnicity, and age; researchers' observation of whether or not they wore hijabs or kufis

\begin{tabular}{|c|c|c|c|c|}
\hline Gender & Race & Ethnicity & Age & Appearance \\
\hline Female & $\begin{array}{l}\text { Half-Moroccan/ } \\
\text { Half-Spanish }\end{array}$ & Not Reported & 21 & Hijab \\
\hline Female & Not Reported & $\begin{array}{l}\text { East African/ } \\
\text { Indian }\end{array}$ & 18 & Hijab \\
\hline Female & Arab & Egyptian & 19 & No Hijab \\
\hline Male & $\begin{array}{l}\text { African-American/ } \\
\text { Arab }\end{array}$ & Not Reported & 20 & No Kufi \\
\hline Male & Arab & Dubai & 21 & No Kufi \\
\hline Male & Asian & Pakistani & 23 & No Kufi \\
\hline Female & Caucasian & Italian \& Polish & 50 & Hijab \\
\hline Female & Arab & Palestinian & 18 & No Hijab \\
\hline Female & Other & Guyanese & 18 & No Hijab \\
\hline Female & Asian & Kazakh & 37 & No Hijab \\
\hline
\end{tabular}

\section{Measures}

A demographic questionnaire was used to collect information about the participants' age, ethnicity, sexual orientation, religion, level of education, years in US, and occupation. Appendix A describes the semistructured protocol designed by the research team to guide the focus group interviews. The protocol consisted of 12 questions that probed for examples of religious microaggressions. Follow-up questions were asked to gain an understanding of the participants' interpretations of events. The protocol questions were designed around the religious microaggression taxonomy discussed earlier (Nadal, Issa, et al., 2010), as well as previous qualitative studies (Nadal, Issa, et al., 2010; Nadal, Wong, et al., 2011; Sue, Nadal, et al., 2008). Open-ended questions were also utilized to give participants an opportunity to discuss microaggressive events that may not be captured by the taxonomy.

\section{Procedures}

Three research team members were assigned to each focus group. Focus groups were each led by one researcher (an Arab female in the first group and a Black male in the second). Two observers (one Black woman and one White man) were present in both groups; they sat separately from the participants and were present to identify participants' nonverbal behaviors (e.g., head nodding, smiling, and other facial expressions). Utilizing an observer is a common practice in qualitative research, so that more than one person can interpret group behaviors and dynamics (Krueger \& Casey, 2000). The focus groups took place in an enclosed private room at two universities in the American Northeast. 
Research participants were assigned to focus groups based on their location and availability. No financial compensation was offered. A list of possible counseling facilities were handed out, informed consent forms were signed by all participants prior to the commencement of the focus group, and participants indicated their agreement to be audio-taped. The interviewer provided a definition of microaggressions, asked open-ended questions about experiences with religious microaggressions, allowed participants to respond in their own time, and probed with follow-up questions when appropriate. Each focus group lasted approximately 50 minutes. The interviewer and observers convened for approximately 15 minutes once the group had concluded to process their experience, including observed personal reactions, emergent themes, social climate, and any problematic issues.

The focus group was audio-taped and then transcribed verbatim with identifying information removed. The transcripts were checked for accuracy by both the interviewer and observer prior to data analysis. Next a directed content analysis was used to qualitatively analyze the data. The goal of a directed approach to content analysis is "to validate or extend conceptually a theoretical framework or theory" (Hsieh \& Shannon, 2005, p. 1281). The aim of the present study was to validate (or enhance) the religious microaggressions taxonomy (Nadal, Issa, et al., 2010), focusing specifically on Muslim experiences. Using the taxonomy, the research team members worked independently to identify key concepts or variables as the initial coding categories. Next, the research team met as a whole and developed initial definitions of the six categories (i.e., Endorsing Religious Stereotypes, Assumption of Religious Homogeneity, etc.) that were identified. Each individual member of the team then carefully reviewed each transcript, taking note of all text that appeared to describe a participant's interpretation or description of a microaggression experience. Team members assigned each microaggression experience to whatever theme or themes they thought the quote could represent. If an example did not fit under any of the proposed themes, the quote was still set aside to potentially be included as an underdeveloped theme or a new theme not recognized by previous research. Examples that were determined by specific team members to fit more than one theme were later discussed by the group who, as a whole, came to a consensus as to which theme the example fit best. The researchers also came to a consensus on determining codes for data that could not be classified via the proposed taxonomy.

Next, the researchers provided an external auditor with the themes and examples of quotes under each theme. The auditor initially worked independently from the other researchers and was included in an attempt to minimize the bias that can occur through group conformity or group dynamics. The auditor, who is an expert on microaggression literature, is not affiliated with the institution where the research was conducted; thus, he was able to offer 
constructive feedback to the rest of the team in an honest and direct way. After independently reviewing the group's coded transcripts and chosen quotations for accuracy, the auditor provided feedback to the team. The team reconvened, and based on the auditor's feedback, revised their analysis when necessary. After the auditor's approval, the team then collaborated to select the most fitting or profound quotations from the transcripts that best illustrated the identified themes. The auditor reviewed the final analysis and approved the teams' collaborative work.

\section{Results}

Six themes emerged from the analysis of the transcriptions. These themes included: (1) Endorsing Religious Stereotypes of Muslims as Terrorists, (2) Pathology of the Muslim Religion, (3) Assumption of Religious Homogeneity, (4) Exoticization, (5) Islamophobic or Mocking Language, and (6) Alien in Own Land. All six themes were derived from robust examples endorsed by multiple participants from both focus groups. The first four themes (Endorsing Religious Stereotypes, Pathology of the Muslim Religion, Assumption of Religious Homogeneity, and Exoticization) support those proposed by Nadal, Issa, and colleagues' (2010) religious microaggression taxonomy. The last two themes (Islamophobic/Mocking Language and Alien in Own Land) were not included from the original theoretical religious microaggression taxonomy; however the amount of examples from both focus groups suggests that these two categories of microaggressions are pervasive in the lives of these Muslim participants. There was one underdeveloped theme, Assumption of Christianity as Normal, but there were not enough examples to generalize the experience of participants across both focus groups. This next section will introduce these themes, along with supporting examples, to demonstrate the types of religious microaggressions these Muslim participants experience. When possible, pseudonyms will be used to protect the identities of the participants; however some first names are used because they are pertinent to the description of certain incidents.

\section{Theme 1: Endorsing Religious Stereotypes of Muslims as Terrorists}

This theme occurs when non-Muslim people assume that all Muslim people are affiliated with terrorism in some way. This sends the message that Muslim people are violent, evil people who should not be trusted. Participants overwhelmingly shared incidents that endorsed this theme, with many describing experiences that were clearly malicious and overtly Islamophobic. For example, 
a participant relayed an incident that she and her mother experienced when walking down the street:

A truck driver said to my mom, "Say hi to Osama." And that was like kind of the worse thing ... you know what she did? [laughs] She said, "I will." [laughs] She made them think that. [laughs] Only because what was she supposed to say? She really didn't know Osama [Bin Laden], but, I mean, just to make them feel stupid, she said that.

While this incident is an example of overt Islamophobia, some participants spoke about statements and behaviors that may be subtler in nature. In these instances, participants identified the incident as being discriminatory, but they may not have had enough evidence to "prove" that Islamophobia was involved. A common experience shared by participants included being randomly searched at airports. One female participant shares:

In the airport, one time, I had my passport with me and I was going from Holland from the Netherlands to Egypt. And the security guard, I was walking the airport alone, the security guard stopped me and was like let me check your passport and like okay ... And I gave him passport, and he looks at my passport, and [says] "Okay you come with me." I'm like okay, so I went with him and he was like the picture doesn't look like you.

While the security guard did not mention anything related to her religious background (or his stereotypes of Muslims as terrorists), the participant interpreted she was stopped because she was dressed in a hijab. Thus, while the first example was more overt, the second may be identified as a microaggression because of its subtlety and lack of mentioning anything related to religion.

Some incidents under this theme included interactions when non-Muslims may or may not have recognized that their comments were offensive. A White participant who had converted to Islam over five years ago has experienced these stereotypes from her own brother (who is not Muslim):

It was like funny and painful at the same time and we were sitting at a table ... "You have to tell me. You know you got to tell me the truth. You go to mosque and everything like that. When you go, do you ever hear anything like when the next bombing's going to be?"

Perhaps it was not the intention of her brother to be offensive; however, his words caused the participant to feel upset, hurt, or misunderstood. Almost every participant had an example of microaggressions based on stereotypes and agreed that these instances were distressing and frustrating. Participants 
expressed that this stereotyping had existed for years, but that it became much more intense and obvious after September $11^{\text {th }}$.

\section{Theme 2: Pathology of the Muslim Religion}

This theme refers to the conscious (and sometimes unconscious) belief that there is something wrong or abnormal with someone of a different religion, leading to behaviors that convey punishment, judgment, or maltreatment (Nadal, Issa, et al., 2010). Female participants discussed the stares they received when they wore their hijabs. Participants indicated that these stares sometimes communicated hate, while other times these communicated discomfort or curiosity. For example, one participant described a time when a stranger made a comment about how she was dressed:

Once a guy came to me ... in the summer, [and] he was like "Don't you feel hot with the thing you are wearing on your head?" I'm like, "No, I don't feel hot. Why don't you ask the nuns? The nuns wear the same thing." And he was like, "Uhhh, ok, ok."

This remark sends the message traditional Muslim garb is abnormal or weird. The participant defends herself (and her religion) by pointing out that people of other religions have traditional garments that they wear without being questioned or mocked.

Participants discussed how they are often treated differently and consequently have adjusted or changed parts of their Muslim identity or appearance. For example, a participant spoke about not using her Arabic name at work because the children will tease her:

I work with students, so once they find out, they call me [Sarah], because that's my middle name. And at work I allow the students to. They're in junior high so at that age they're very ignorant and not very nice.

Because the participant had been teased in the past for her name, she would rather prevent microaggressions by having her students call her a non-Arabic name. This example is one of many in which it is difficult to attribute whether the microaggression is based on religion, race, ethnicity, or some combination of them all.

Theme 3: Assumption of Religious Homogeneity

When others assume all Muslim individuals share the same experiences, religious practices, or behaviors, they make a judgment that there are no differ- 
ences between members of a certain group, that an entire religious group is completely homogenous. This type of microaggression is different than stereotyping because stereotypes are based on false, unnecessary, or unwarranted prejudice (e.g., assuming that agnostics or atheists don't have morals or that Muslims would be terrorists). Assumption of religious homogeneity is unique from stereotyping in that an individual may be aware (or seem to be aware) of a certain religious or cultural practice, but assumes: (a) there is no flexibility to the practice or tradition, or (b) every single person of the group must engage in such a behavior. For example, one participant described her experience:

People come up to me, like, they don't know between religion and ethnicity, they would come up to me and be like, "You are White, why are you covered?" I was like, “I'm Muslim. I'm Moroccan. I am not Arabic, but I am Muslim." So it's not the same, but for them, it's like if you are covered, you have to be Arabic in order to be Muslim."

In this individual's experiences, people have assumed all Muslims are of Arab descent and therefore do not believe that she is Muslim.

Another participant described an experience in which she was questioned about the religious practices of Muslim individuals, "He was like, 'Well do you guys really pray five times a day?' I was like, 'Uh, well, we all have busy lives so it's impossible for some us to pray five times a day. "In this instance, the man assumed that all Muslims are strict with their practices and that there isn't any room for flexibility. Such a statement also sends a judgmental message that all Muslim people must be the same, while also maintaining that their practices are abnormal in American society.

\section{Theme 4: Exoticization}

An exoticization-themed religious microaggression may occur when someone asks an individual an excessive amount of questions regarding any or all aspects of their religion. These types of microaggressions can also occur when people view particular religions as exotic and or trendy. For example, when fashion designers use religious garments in their designs, a message is communicated that one's religious garments are allowed to be exploited for commercial use and fashion. Participants discussed a few ways in which they felt exoticized. One participant discussed how many celebrities have recently converted to Islam. While the true intentions of these celebrities are not known, a message can be conveyed that Islam is exotic and a new fad among celebrities. Another participant shared an example of exoticization of the Muslim religion on the television show The Office. She explains a scene in which Steve Carrell's character was traveling internationally for his business: 
He asked a female who walks into the office to say that she is from Abu Dhabi and he is like "Pretend that you are from Abu Dhabi. I'm so ashamed of your naked face, I should cover you." And he got his jacket and covered her face and said, "Now you are sexy in your culture."

This incident may be viewed as a religious microaggression because the character is portraying Muslim women as being exotic, different, or unusual, instead of understanding the significance of the religion and of the hijab. While meant to be a joke, Muslim individuals who watch this show may feel saddened that their religion is being portrayed in such a negative and harmful way. This incident may also be considered an environmental microaggression because it takes place on television, thus communicating these hurtful or offensive messages to millions of people who watch it.

\section{Theme 5: Islamophobic and Mocking Language}

This type of microaggression is a new category that was derived after analyzing the transcriptions from the focus groups. This theme involves instances where people make fun of the religion, use hurtful language, and tease the people who subscribe to it. For example, one participant describes a time when one of her students began teasing her:

So I had a student in eighth grade last year where he knew my full last name was [Hussein] and he would speak in this accent but totally not from where I'm from. And he would call me like a Taliban. I felt like, "You need to stop." And it was getting to a point where he started calling me a terrorist at work and I didn't appreciate that.

Because of the environmental microaggressions that may occur on television, perhaps individuals have learned that it is socially acceptable to make fun of Muslim people.

Another example was depicted by a participant who was talking about an experience with one of his teachers when he was an adolescent:

I was in seventh grade and my name is Osama. And when the 9/11 happened, a lot of people picked on me after school ... And one teacher, like, she was doing attendance and she called me Osama bin Laden. So I thought she did it by accident, because the name was on the news a lot and stuff. But [I knew] she was doing it on purpose [because] she kept doing it over and over. 
This theme communicates that Islam is something to be feared or something that is unacceptable. Moreover, participants described how people were blatant in sharing their negative views about Islam. For example:

Um I found a note on the subway. So I just sat there and I found a note saying, "Allah sucks dicks." And I looked at it and I [thought] "What? I, I got so mad that I'm just like why would you do that? Why? And I just, it was like glued on the chair and I just tried to rip it up, rip it up, and rip it up and threw it in the garbage. So I, I was shocked actually to see that! Like there's no respect at all towards it.

Participants reported feeling hurt and disgusted by incidents that involved Islamophobic language. Almost all participants discussed the Islamophobic language that they experienced in their everyday lives. Some participants cited that they believed that people felt comfortable saying negative comments about Muslims, but knew that it would be politically incorrect to say such things about other religious and racial/ethnic groups.

\section{Theme 6: Alien in Own Land}

Sue, Capodilupo, and colleagues (2007) discuss how individuals who were born, raised, or lived a significant amount of time in the US are still often treated like foreigners. For example, one participant shared: "I walked up and he goes, 'What are you, Indonesian?' You know he made it seem like I must be from another country or something." Individuals, such as this participant, may experience situations in which others make them feel as if they do not belong in the US even though they were born in the US or consider the US to be their home. Such experiences communicate that these individuals do not belong in the US, subtly communicating that there is a certain way of being or looking American.

Similarly, another participant discussed comparable and reoccurring experiences that she experiences regularly:

They are always telling us: "Go back to your country!" [But] this is our country. We're obviously living here ... Who are you to tell me to go back anywhere? I was born here I should be able to live here. And if our parents came here for better opportunities, why should they even be allowed to say that?"

Finally, a participant discussed an incident in which she introduced herself during class in a large lecture hall: "Everyone just got up and was just like staring at 
me ... but they didn't say anything." Because of her Arabic name, she felt that everyone went out of their way to look at her. But although no one said anything blatantly discriminatory, she still felt uncomfortable by her peers. In each of these scenarios the enactors communicated a message that the participants did not belong, were not welcome, or both. As a result, participants reported feeling angry, sad, belittled, and frustrated. Again, it is unclear of whether these microaggressions are based on solely on religion, race, ethnicity, or some combination of them all.

\section{Discussion}

Although there has been an increased interest in the impact of the 9/11 terrorist attacks on Muslims living in the US (Kira et al., 2010; Rippy \& Newman, 2008), little research has been conducted on the psychological impact of religious microaggressions. While Muslims in the US have reported an increase in their experiences of overt discrimination (CAIR, 2003, 2008), attention must also be paid to the covert discrimination that these individuals are likely to face on a daily basis. The results of the present pilot study support four themes from the proposed taxonomy of religious microaggressions proposed by Nadal, Issa, and colleagues (2010), along with two emerging themes based on experiences from participants in our study.

As with other types of microaggressions, the examples of religious microaggressions experienced by the participants were referred to as both intentional and unintentional. Sometimes the enactor was either aware or unaware of the connotation and implications of her or his words or actions (e.g., someone using Islamophobic language to hurt someone's feelings), but other times, enactors were unlikely aware of their actions (e.g., an individual who stares at a Muslim woman wearing a hijab, even out of curiosity, may not recognize the hurtful message that is communicated). However, participants discussed many instances of discrimination that were blatant and even verbally assaultive. Sue, Capodilupo, and colleagues (2007) described that microaggressions can take the form of microassaults (e.g., old fashioned, conscious, and intentional racism) and microinsults (e.g., subtle behavioral and verbal communications). This suggests that although racism is said to have diminished, perhaps Islamophobia is still rampant and Muslim Americans still experience blatant discrimination on a regular basis.

Two of the themes from the original religious microaggression taxonomy were not supported by the participants: Assumption of One's Own Religion as the Norm and Denial of Religious Prejudice. There are two possibilities for this outcome. First, examples of how one's religion is viewed as the norm are often described as being subtle and part of American culture. For example, Nadal 
(2008) described Christmas decorations in public spaces (including government buildings) as being a common occurrence and that non-Christians may not recognize this as being discriminatory. Perhaps Muslims (and other nonChristians) are so socialized to believe that certain behaviors and environments are normalized parts of American culture that it simply becomes difficult to identify. Second, denial of religious prejudice is a microaggression that usually requires individuals to have difficult conversations about religion with others, which would lead to these invalidating statements. Perhaps these individuals did not experience such microaggressions because they avoid engaging in conversations in which these may occur.

As aforementioned, the Muslim community in the US is so diverse in terms of race (with the largest populations being Arab, Asian, and Black) and ethnicity (with people from various countries like Syria, India, the Philippines, and Spain). Thus, it is important to recognize that the microaggressions that Muslim Americans experience may not only be due to religion, but also due to race, ethnicity, gender, or some combination of all of these. For example, if a Muslim, Asian Indian woman experiences a microaggression in which she is treated as an "alien in her own land," it may be due to her religion (Muslim), race (Asian), ethnicity (Indian), gender (woman), or some combination of all. At the same time, perhaps her experiences with microaggressions may be completely different from a non-Muslim Asian Indian woman or a Black woman who is Muslim. Thus, it is important to remember that intersectional identities may result in unique and complicated types of microaggressions in people's lives.

Further, the idea of "passing" is an important concept in understanding microaggressions toward Muslim Americans. Some participants reported that they are less traditional and may not wear religious garments at all (or only on holidays). Thus, the types of microaggressions that these individuals experience may be different than those experienced by Muslims who wear traditional clothes on a regular basis. This idea of "passing" was introduced in the literature on multiracial microaggressions (Johnston \& Nadal, 2010), citing that when an individual is mistaken or "passes" for the dominant group, she or he may be afforded more privilege than those who do not (or cannot) pass. Perhaps Muslim individuals who do "pass" as non-Muslim may not experience the same types, or amounts, of microaggressions as people who are easily identified as Muslim. At the same time, it is possible that when someone can "pass" that microaggressions may be much more frequent, because others may assume the individual to be non-Muslim and unknowingly communicate negative messages about Islam. Future research on the concept of passing is necessary, in order to understand how microaggressions impact the lives of the broad ranges of Muslim people. 
Finally, it is important to note that microaggressions that are perpetuated in the media may have a detrimental impact on the stereotypes non-Muslims develop, as well on the psychological health of Muslims themselves. Specifically, general society's stereotypes about Muslims as terrorists may stem from the overtly Islamophobic statements made by politicians and media commentators in the public eye. For example, when Fox News host Bill O'Reilly stated that "Muslims killed us on 9/11" on the television show The View, it is clear that his comment was rooted in his Islamophobic bias. However, the statement still has microaggressive qualities because of his intention. While he was conscious of his words, his intention may not have been to attack all Muslims; in fact, in a later interview he stated, "if anyone felt that I was demeaning all Muslims, I apologize" (Thomas, 2010). This unintentionally offensive comment is similar to the example given by one participant regarding the television sitcom The Office. However, even if someone's intention is not malicious, the mere fact that such prejudice is so pervasive in the media, stereotypes about Muslim people are perpetuated, which in turn may lead to both overt and covert discrimination on interpersonal levels. Further, negative images of Muslims in the media may have detrimental impacts on the self-esteem, mental health, and identities of Muslim people. Thus, it is necessary for media and other institutions to be much more vigilant in preventing these types of stereotypes from continuing, in order to decrease microaggressions in everyday life and to promote optimal mental health for Muslim people.

\section{Implications for Research and Clinical Practice}

There are many implications in this study for Muslim mental health and for psychology in general. First, it is crucial for academic literature to focus specifically on the mental health and lived experiences of Muslim Americans. Although they are a growing population in the US, there is little known or written about their experiences with psychological well-being, identity development, acculturation processes, mental health treatment, experiences with discrimination, or other pertinent issues. Second, it is important for the microaggression literature (i.e., both empirical research and theoretical models) to expand to include the experience of religious microaggressions toward Muslims and other religious minority groups. Given that Islamophobic discrimination has grown exponentially since $9 / 11$, it is necessary for mental health practitioners to be aware of the impact of discrimination on the mental health of these individuals, in order to provide the most effective treatment for them.

Further, in order to maintain ethical standards of cultural competence of various governing boards (e.g., American Psychological Association, American Counseling Association), clinicians must expand their knowledge and skill base 
to include Muslims (and other religious minority groups). Clinicians must recognize the types of microaggressions their Muslim clients may experience in their everyday lives, as well as potential microaggressions that may occur in therapy. Practitioners must be conscious of their own biases and stereotypes about Muslims, and how these stereotypes may unintentionally manifest in psychotherapy. For example, if a non-Muslim female psychologist assumes that a hijab is oppressive against women, she may unconsciously try to steer her client away from covering, instead of understanding the significance of the hijab in her Muslim client's life.

Leaders in school systems and other institutions must be aware of the ways that Muslim young people are discriminated against, both blatantly and subtly, and how such messages impact their identities and development. For example, one study in the United Kingdom found that Muslim students were often bullied by their peers because of their religion (Eslea \& Mukhtar, 2000). Because Islamophobic stereotypes are often viewed as acceptable in the media, it is important for educators to combat these prejudices by teaching young people about equality and acceptance, as well as the hurtfulness of bullying and other forms of discrimination. In increasing this awareness in individuals at an early age, it is hoped that the stigma toward Muslim people (and any marginalized group) will decrease and that the mental health of Muslim Americans (and others) will improve.

While the results of this pilot study were rich, there are several possibilities for future research in this area. First, because racial discrimination has been found to be related to mental health problems (e.g., depression, substance use) and physical ailments (e.g., cardiovascular disease), research may examine religious microaggressions and their impact on physical and mental health disparities in Muslim American communities. Furthermore, researchers may want to examine the coping processes and reactions to microaggressions by Muslim Americans, as well as the protective factors that help them to resiliently manage experiences with discrimination. Finally, researchers may investigate the impact of religious microaggressions on other religious minority groups (i.e., Jews, people who do not identify with any religion, Hindus, etc.), understanding the types of microaggressions these individuals experience and the ways that they cope with these microaggressions as well.

\section{Limitations}

It is important to acknowledge that our study should be considered a pilot, especially given the small sample size and the limited generalizabilty to the entire Muslim community. Given the qualitative framework and purposive participant recruitment process employed in our study, we cannot suggest that our results represent the entire experience of the Muslim American population. 
Thus, it is important for both qualitative and quantitative studies with larger sample sizes to emerge, in order to gain a better understanding of the Muslim experience. Second, we were not able to investigate differences in gender, age, race, as well as other demographics that likely contribute to Muslim Americans' experiences with microaggressions. Third, given that Muslim Americans represent a wide array of generational statuses, it is likely that acculturation issues (e.g., language use, cultural customs, etc.) play a role in how microaggressions manifest for Muslim Americans; however, our methodology did not allow us to examine acculturation in this study.

\section{Conclusion}

The current study is the first known report to examine the experiences of religious microaggressions by Muslim Americans. As demonstrated by the participants' responses, Muslims are subjected to various types of religious microaggressions such as being stereotyped as a terrorist, having others pathologize or exoticize them or their religion, and being the target of Islamophobic or mocking language (to name a few). Muslims often endure negative media messages in both the news and on fictional television shows. Being the victim of such covert discrimination on a consistent basis can have an additive affect on one's mental health and ability to function daily. Thus, in the same way that efforts have been made for racial equality for African Americans, Latina/ os, Asian Americans, and Native Americans, efforts must be made to decrease discrimination toward Muslim Americans, in order to promote their positive mental health and well-beings.

\section{References}

Bukhari, Z. R. (2003). Demography, identity, space: Defining American Muslims. In P. Strum \& D. Tarantolo (Eds.), Muslims in the United States: Demography, beliefs, institutions (pp. 9-10). Washington, DC: Woodrow Wilson International Center for Scholars.

Capodilupo, C. M., Nadal, K. L., Corman, L., Hamit, S., Lyons, O. B., \& Weinberg, A. (2010). The manifestation of gender microaggressions. In D. W. Sue (Ed.), Microaggressions and marginality: Manifestation, dynamics, and impact (pp. 193-216). New York: Wiley \& Sons.

Council on American-Islamic Relations. (2003). The status of Muslim civil rights in the United States: Guilt by association. Washington, DC: CAIR.

Council on American-Islamic Relations. (2008). The status of Muslim civil rights in the United States 2008. Washington, DC: CAIR. Retrieved on February 1, 2009 from http://www.cair.com/Portals/0/pdf/civilrights2008.pdf

Eslea, M., \& Mukhtar, K. (2000). Bullying and racism among Asian schoolchildren in Britain. Educational Research, 42, 207-217. 
Fassinger, R. E. (2005). Paradigms, praxis, problems, and promise: Grounded theory in counseling psychology research. Journal of Counseling Psychology, 52, 156-166.

Fine, M. (1992). Passion, politics, and power. In M. Fine (Ed.), Disruptive voices: The possibilities of feminist research (pp. 205-231). Ann Arbor: University of Michigan Press.

Franklin, A. J. (2004). From brotherhood to manhood: How black men rescue their relationships and dreams from the invisibility syndrome. Hoboken, NJ: Wiley.

Hsieh, H-F., \& Shannon, S. E. (2005). Three approaches to qualitative content analysis. Qualitative Health Research, 15, 1277-1288.

Johnston, M. P., \& Nadal, K. L. (2010). Multiracial microaggressions: Exposing monoracism in everyday life and clinical practice. In D. W. Sue (Ed.), Microaggressions and marginality: Manifestation, dynamics, and impact (pp. 123-144). New York: Wiley \& Sons.

Kira, I. A., Lewandowski, L., Templin, T., Ramaswamy, V., Ozkan, B., \& Mohanesh, J. (2010). The effects of perceived discrimination and backlash on Iraqi refugees' mental and physical health. Journal of Muslim Mental Health, 5, 59-81.

Krueger, R. A., \& Casey, M. A. (2009). Focus groups: A practical guide for applied research (4th Edition). Thousand Oaks, CA: Sage.

López, F. B. (2011). Towards a definition of Islamophobia: Approximations of the early twentieth century. Ethnic and Racial Studies, 34, 556-573.

Morrow, S. L., \& Smith, M. L. (2000). Qualitative research for counseling psychology. In S. D. Brown \& R. W. Lent (Eds.), Handbook of counseling psychology, 3rd Edition (pp. 199-230). Hoboken, NJ: John Wiley \& Sons.

Nadal, K. L. (2008). Preventing racial, ethnic, gender, sexual minority, disability, and religious microaggressions: Recommendations for promoting positive mental health. Prevention in Counseling Psychology: Theory, Research, Practice and Training, 2(1), 22-27.

Nadal, K. L. (2010). Gender microaggressions: Implications for mental health. In M. A. Paludi (Ed.), Feminism and womens rights worldwide, Volume 2: Mental and physical health (pp. 155-175). Santa Barbara, CA: Praeger.

Nadal, K. L. (2011). The Racial and Ethnic Microaggressions Scale (REMS): Construction, reliability, and validity. Journal of Counseling Psychology, 58, 470-480.

Nadal, K. L., Issa, M., Griffin, K. E., Hamit, S., \& Lyons, O. B. (2010). Religious microaggressions in the United States: Mental health implications for religious minority groups. In D. W. Sue (Ed.), Microaggressions and marginality: Manifestation, dynamics, and impact (pp. 287-310). New York: Wiley \& Sons.

Nadal, K. L., Issa, M., Leon, J., Meterko, V., Wideman, M., \& Wong, Y. (2011). Sexual orientation microaggressions: "Death by a thousand cuts" for lesbian, gay, and bisexual youth. Journal of LGBT Youth, 8, 234-259.

Nadal, K. L., Rivera, D. P., \& Corpus, M. J. H. (2010). Sexual orientation and transgender microaggressions in everyday life: Implications for mental health and counseling. In D. W. Sue (Ed.), Microaggressions and marginality: Manifestation, dynamics, and impact (pp. 217-240). New York: Wiley \& Sons.

Nadal, K. L., Wong, Y., Griffin, K., Sriken, J., Vargas, V., Wideman, M., \& Kolawole, A. (2011). Microaggressions and the multiracial experience. International Journal of Humanities and Social Sciences, 1(7), 36-44.

Reid, L. D., \& Radhakrishnan, P. (2003). Race matters: The relation between race and general campus climate. Cultural Diversity and Ethnic Minority Psychology, 9, 263275. 
Rippy, A. E., \& Newman, E. (2006). Perceived religious discrimination and its relationship to anxiety and paranoia among Muslim Americans. Journal of Muslim Mental Health, 1, 5-20.

Rippy, A. E., \& Newman, E. (2008). Adaptation of a scale of race-related stress for use with Muslim Americans. Journal of Muslim Mental Health, 3, 53-68.

Sellers, R. M., \& Shelton, J. N. (2003). The role of racial identity in perceived racial discrimination. Journal of Personality and Social Psychology, 84, 1079-1092.

Shelton, K., \& Delgado-Romero, E. A. (2011). Sexual orientation microaggressions: The experience of lesbian, gay, bisexual, and queer clients in psychotherapy. Journal of Counseling Psychology, 58(2), 210-221.

Sheridan, L. P. (2006). Islamophobia pre- and post-September $11^{\text {th }}, 2001$. Journal of Interpersonal Violence, 21, 317-336.

Strumm, P. (2003). Executive summary. In P. Strum \& D. Tarantolo (Eds.), Muslims the United States: Demography, beliefs, institutions (pp. 9-10). Washington, DC: Woodrow Wilson International Center for Scholars.

Sue, D. W., Bucceri, J., Lin, A. I., Nadal, K. L., \& Torino, G. C. (2007). Racial microaggressions and the Asian American experience. Cultural Diversity and Ethnic Minority Psychology, 13(1), 72-81.

Sue, D. W., Capodilupo, C. M., \& Holder, A. M. B. (2008). Racial microaggressions in the life experience of Black Americans. Professional Psychology: Research and Practice, 39, 329-336.

Sue, D. W., Capodilupo, C. M., Torino, G. C., Bucceri, J. M., Holder, A. M. B., Nadal, K. L., et al. (2007). Racial microaggressions in everyday life: Implications for clinical practice. American Psychologist, 62, 271-286.

Sue, D. W., Lin, A. I., Torino, G. C., Capodilupo, C. M., \& Rivera, D. P. (2009). Racial microaggressions and difficult dialogues in the classroom. Cultural Diversity and Ethnic Minority Psychology, 15, 183-190.

Sue, D. W., Nadal, K. L., Capodilupo, C. M., Lin, A. I., Torino, G. C., \& Rivera, D. P. (2008). Racial microaggressions against Black Americans: Implications for counseling. Journal of Counseling and Development, 86, 330-338.

Thomas, D. (2010, October 14). Bill O’Reilly On "The View": "Muslims Killed Us On 9/11. CBS News. Retrieved November 11, 2010 from http://www.cbsnews. com/8301-31749_162-20019660-10391698.html 


\section{Appendix A: Interview Questions}

\section{Introduction}

$\mathrm{Hi}$, my name is . Thank you very much for coming today to participate in this focus group. The purpose of this group is to understand the experiences of subtle discrimination on specific racial groups, ethnic groups, genders, sexual and religious minority groups. Ok, so, I am going to give you a form, which basically states that your participation in this group is entirely voluntary and that you may decline to participate and leave the interview at any time. Please read this sheet carefully before signing it. It discusses potential risks to you as an interviewee as well as the use of audio taping during this session.

\section{Statement of Confidentiality}

Before we start, I encourage you to share your experiences openly and honestly with me. I will be tape recording this session in an effort to maintain the integrity of our dialogue. However, your identity will remain confidential and only the researchers will have access to this tape. This discussion is to be considered confidential and I would hope that you will all respect each other's right to privacy by not repeating any portion of this discussion outside the session. Do you all agree to keep all information confidential?

\section{Opening Question}

1. So today we're going to be talking about microaggressions. Microaggressions can be defined as brief statements or behaviors that send denigrating and hurtful messages towards different groups. Because of our current politically correct society, many researchers have noticed that religious discrimination is much more subtle than it may have been 10,20 , or 30 years ago. Today, you are all gathered as a group of Muslim individuals so we will be discussing religious microaggressions. At this time, I would like you to introduce yourself and tell me about your initial thoughts about microaggressions.

\section{Interview Questions:}

2. Think about a time when you may have been blatantly discriminated against because of your religion. Describe the scenario as best as you can.

a. How did you react in this situation? 
b. What do you perceive was the message that was being conveyed to you?

c. How did you feel after the event? Several days after the event? Several months after the event?

3. Think about a time when you may have been subtly discriminated against because of your religion. Describe the scenario as best as you can.

a. How did you react in this situation?

b. What do you perceive was the message that was being conveyed to you?

c. How did you feel after the event? Several days after the event? Several months after the event?

4. Describe a time when a member of another religion has made you feel uncomfortable because of your religion.

a. How did you react in this situation?

b. What do you perceive was the message that was being conveyed to you?

d. How did you feel after the event? Several days after the event? Several months after the event?

5. Describe a time in which someone had made a disparaging remark or used derogatory language about your religion.

a. How did you react in this situation?

b. What do you perceive was the message that was being conveyed to you?

c. How did you feel after the event? Several days after the event? Several months after the event?

6. Describe a circumstance in which someone's behavior made you feel uncomfortable, hurt, or devalued because of your religion.

a. How did you react in this situation?

b. What do you perceive was the message that was being conveyed to you?

c. How did you feel after the event? Several days after the event? Several months after the event?

7. Describe a situation where you felt physically or emotionally unsafe because of your religion.

a. How did you react in this situation?

b. What do you perceive was the message that was being conveyed to you? 
c. How did you feel after the event? Several days after the event? Several months after the event?

8. Describe a situation where you felt pressured to act a certain way because of your religion.

a. How did you react in this situation?

b. What do you perceive was the message that was being conveyed to you?

c. How did you feel after the event? Several days after the event? Several months after the event?

9. Describe a situation where you felt that someone treated you a certain way because of stereotypes about your religion.

a. How did you react in this situation?

b. What do you perceive was the message that was being conveyed to you?

c. How did you feel after the event? Several days after the event? Several months after the event?

10. Describe a time when you felt that society (through the media, school system, religion, or other institutions) may have sent negative messages about your religion.

a. How did you react in this situation?

b. What do you perceive was the message that was being conveyed to you?

11. What impact do these experiences with subtle religious discrimination have on your mental health?

\section{Acknowledgement and contact information:}

We want to send a special thank you to Marie-Anne Issa, Raymond Tebout, Kolawole Ajayi, and the rest of our research team members who have assisted with our microaggression research. Correspondence regarding this manuscript should be addressed to Kevin L. Nadal, Ph.D. John Jay College of Criminal Justice - City University of New York, 445 W. $59^{\text {th }}$ Street, New York, NY 10019, (212) 237-8795,knadal@jjay.cuny.edu 